\title{
Removal of Residual Pesticides in Vegetables Using Ozone Microbubbles
}

\author{
Masahiko Tamaki and Hiromi Ikeura
}

Additional information is available at the end of the chapter

http://dx.doi.org/10.5772/48744

\section{Introduction}

The present agriculture has enabled mass and stable production by using of agricultural pesticides. However, agricultural pesticides can have an adverse effect on the environment in addition to being harmful to humans, animals and fishes. The health hazard to the farmer as well as the residue in crops is also a global problem. Recently, the safety of crops including contamination with agricultural pesticides is a major concern to both the producer and consumer, and the development of a method to remove the pesticides before marketing has been eagerly awaited. In Japan, about 600 agricultural pesticides are included in the Positive List established in 2006. Since agricultural crops cannot be marketed when they contain pesticides exceeding the residual limit, the development of a measure for eliminating residual pesticides in crops is now an important issue (Yamaguchi, 2006).

Ozone $\left(\mathrm{O}_{3}\right)$ is the natural substance in the atmosphere and one of the most potent sanitizers against a wide spectrum of microorganisms (Khadre et al., 2001). $\mathrm{O}_{3}$ is generated by the passage of air or oxygen gas through a high voltage electrical discharge or by ultraviolet light irradiation (Mahapatra et al., 2005), then has a strong oxidative power, and is used for sterilization, virus inactivation, deodorization, bleaching (decoloration), decomposition of organic matter, mycotoxin degradation and others (Cataldo, 2008; Karaca and Velioglu, 2009; Karaca et al., 2010; Takahashi et al., 2007a). In addition, $\mathrm{O}_{3}$ is changed to oxygen by autolysis and does not harm the flavor of vegetables and fruits ( $\mathrm{Li}$ and Tsuge, 2006). Therefore, $\mathrm{O}_{3}$ is considered to be most suitable for removing residual pesticides from vegetables and fruits and controlling microbes of food safety concern (Selma et al., 2008; Gabler et al., 2010).The threshold concentration of $\mathrm{O}_{3}$ for continuous human exposure is $0.075 \mu \mathrm{L} / \mathrm{L}$ (US Environmental Protection Agency, 2008). Although there are many studies on the removal of pesticides using $\mathrm{O}_{3}$ for water purifications in waste water, there are 
several reports on the use of $\mathrm{O}_{3}$ to remove residual pesticide in vegetables and fruits (Daidai et al., 2007; Hwang et al., 2001a; Hwang et al., 2001b; Hwang et al., 2002; Karaca and Velioglu, 2007; Ong et al., 1995; Wu et al., 2007a; Gabler et al., 2010).

Microbubbles (MB) are less than $50 \mu \mathrm{m}$ in diameter and have special properties such as generation of free radicals, self-pressurization and negative charge, and their use in the field of food science and agriculture is attracting attention (Sumikura et al., 2007; Takahashi et al., 2007b). Millibubbles generated by using an air pump are 2-3 mm in diameter, rapidly rise in water and burst at the water surface. Therefore, the solubility of the gas in water is very low. On the other hand, MB rise in water slowly and the interior gas is completely dissolved in water (Takahashi et al., 2007a).

Up to now, growth promotion of lettuce in hydroponic cultures with air MB (Park and Kurata, 2009) and inactivation of Escherichia coli using $\mathrm{CO}_{2} \mathrm{MB}$ (Kobayashi et al., 2009) have been reported. In addition, reports on disinfecting wastewater using ozone $\left(\mathrm{O}_{3}\right) \mathrm{MB}$ have discussed their strong disinfectant activities and relative long-term durability in water (Sumikura et al., 2007; Chu et al., 2007; Chu et al., 2008a; Chu et al., 2008b).

There are two types of $\mathrm{O}_{3} \mathrm{MB}(\mathrm{OMB})$ generators, a decompression type and a gas-water circulation type. In the former, a sufficient amount of gas is dissolved in water under a 3-4 atmospheric pressure to cause a supersaturated condition (Figure 1-A). Under such a condition, supersaturated gas is unstable and escapes from the water generating a large amount of air bubbles, which are MB. In the latter, gas is introduced into the water vortex, and the formed gas bubbles are broken into MB by breaking the vortex (Figure 1-B) (Takahashi, 2009).

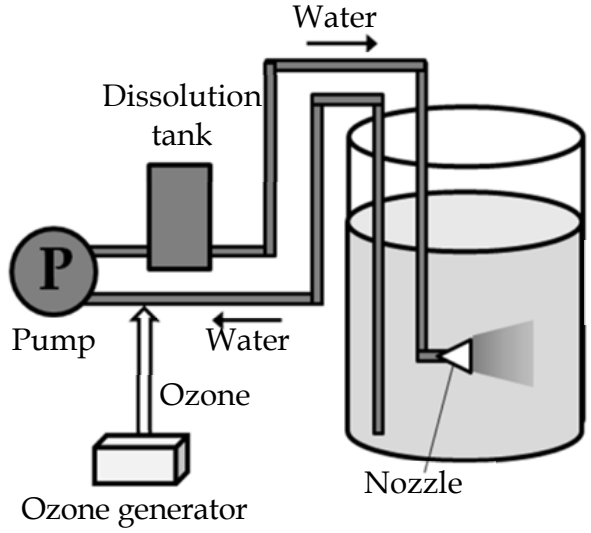

A

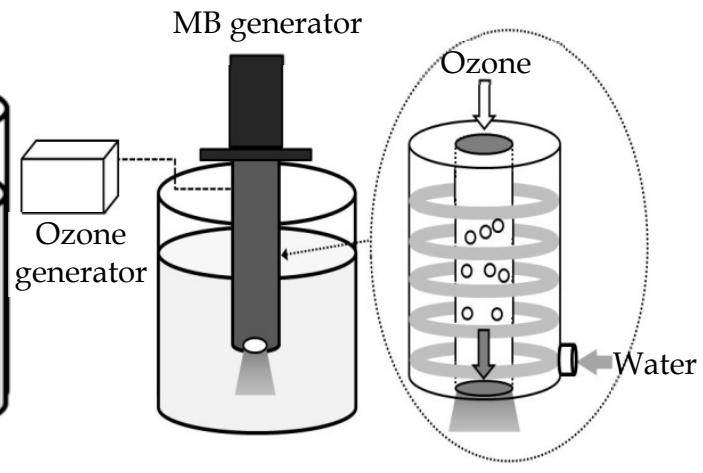

B

Figure 1. Schematic diagrams used for MB generation. (A) The decompression-type MB generator, (B) the gas-water circulating-type MB generator. 
By the way, although there have been several studies on the use of $\mathrm{O}_{3}$ millibubble for removing residual pesticides from vegetables and fruits, few studies have reported on the use of OMB to remove them. Therefore, since microbubbled gas is highly soluble in water and $\mathrm{O}_{3}$ is a powerful decomposer of organic matter, $\mathrm{OMB}$ were expected to remove residual pesticides efficiently from vegetables and fruits.

No comparative studies exist on the effects of OMB generated by different methods on the removal of residual pesticides in vegetables. In this study, we examined 1) the effects of OMB generated by different methods and 2) the effects of OMB dissolved by different concentrations on the removal of pesticide (fenitrothion, FT) infiltrated into vegetables with different shapes. Since FT has been utilized widely as pesticide and acaricide, or mixture with organophosphorus agent, carbamate, pyrethroid and antibiotic in Japan, we used it in this study.

\section{Materials and methods}

\subsection{Materials}

Lettuce, cherry tomatoes and strawberries used in this study were purchased from a supermarket in Kawasaki city. A common organic phosphorous pesticide, fenitrothion, (Sumithion emulsion, $50 \%$ of MEP) and $\mathrm{d}_{6}$-fenitrothion were obtained from Sumitomo Chemical Co. Ltd. (Osaka, Japan) and Kanto Chemical Co. Ltd. (Tokyo, Japan), respectively. The structure of FT $\left(\mathrm{C}_{9} \mathrm{H}_{12} \mathrm{NO}_{5} \mathrm{PS}, \mathrm{MW} 277.25\right)$ is shown in Figure 2. FT agent contains $50 \%$ of O,O-Dimethyl-O-(3-methyl-4-nitrophenyl) thiophosphate, $50 \%$ of organic solvent and surfactant agent, and generally it is used by 1000 -fold dilution with tap water.

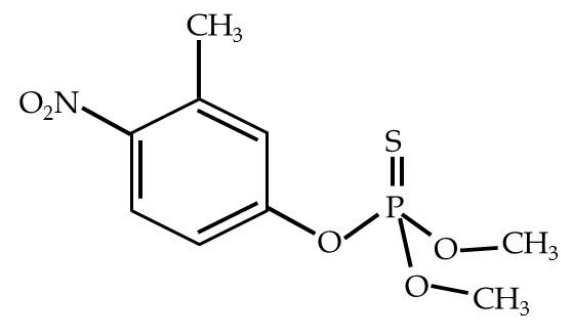

Figure 2. Chemical structure of fenitrothion

\subsection{Treatment with agricultural pesticide}

FT was 1000-fold diluted in tap water, and three drops of a spreading agent (Haiten power, Hokko Sangyo, Co., Ltd. Tokyo, Japan) were added. The concentration of FT solution was $500 \mathrm{ppm}$. Lettuce leaves and fruits of cherry tomatoes and strawberries were immersed in this solution $(60 \mathrm{~L})$ for $1 \mathrm{~min}$ and left in a cool dark room for $24 \mathrm{hr}$ to infiltrate FT into vegetables. Thereafter, they were washed in tap water for $1 \mathrm{~min}$ and treated with $\mathrm{O}_{3}$ as follows. 


\section{3. $\mathrm{O}_{3}$ treatment}

\subsubsection{Experiment 1}

Forty liters of tap water was pooled in a cylindrical vessel $(55 \mathrm{~cm} \times 32 \mathrm{~cm}$ i.d.) and kept at 20 ${ }^{\circ} \mathrm{C}$ in a room to remove chlorine in tap water for $24 \mathrm{hr}$. We confirmed that all the chlorine had been removed $24 \mathrm{hr}$ later by a chlorine comparator (Photometer CL, OYWT-31, OYALOX Co., Ltd., Tokyo, Japan). OMB was generated in dechlorinated water by using a MB generator of a gas-water circulation type (FS101-L1, Fuki Co. Ltd., Saitama, Japan) or a decompression type (20NEDO4S, Shigen-Kaihatsu Co. Ltd., Kanagawa, Japan) combined with an $\mathrm{O}_{3}$ generator (ED-OG-A10, Ecodesign Co. Ltd., Saitama, Japan) at a flow rate of 2.5 $\mathrm{L} / \mathrm{min}$. Under this condition, no more than $2.0 \mathrm{ppm}$ of $\mathrm{O}_{3}$ could be dissolved. Therefore, $\mathrm{O}_{3}$ generation was stopped when the concentration of dissolved $\mathrm{O}_{3}$ reached $2.0 \mathrm{ppm}$ and three kinds of vegetables were immersed in the solutions for 0,5 , or $10 \mathrm{~min}$. Solution temperature was kept at $20{ }^{\circ} \mathrm{C}$ in all treatments. In addition, the concentration of dissolved $\mathrm{O}_{3}$ was measured with a dissolved $\mathrm{O}_{3}$ meter (OZ-21P, DKK-TOA Co. Ltd., Tokyo, Japan), by shaking the electrode with $10 \mathrm{~cm} / \mathrm{s}$ in solutions. Analyses were run in triplicate.

\subsubsection{Experiment 2}

$\mathrm{O}_{3}$ millibubbles (OMLB) were generated in the dechlorinated water with an ED-OG-A10 $\mathrm{O}_{3}$ generator at a flow rate of $2.5 \mathrm{~L} / \mathrm{min}$. The maximum amount of $\mathrm{O}_{3}$ that could be dissolved under these conditions was $0.2 \mathrm{ppm}$, so $\mathrm{O}_{3}$ generation was stopped when the concentration of dissolved $\mathrm{O}_{3}$ reached $0.2 \mathrm{ppm}$. Then the vegetables were immersed in this solution for 0 , 5 , or $10 \mathrm{~min}$.

$\mathrm{OMB}$ were generated in the dechlorinated water using a gas-water circulation type $\mathrm{MB}$ generator together with the ED-OG-A10 $\mathrm{O}_{3}$ generator described above. Ozonated water solutions were produced containing $0.5,1.0$, or $2.0 \mathrm{ppm}$ dissolved $\mathrm{O}_{3}$. Then, the vegetables were immersed in these solutions for 0,5 , or $10 \mathrm{~min}$. Treatment with OMB solution containing $0.2 \mathrm{ppm}$ dissolved $\mathrm{O}_{3}$ was not fully tested because a preliminary experiment showed that its pesticide-removing activity was not significantly different from that of the OMLB solution.

A further treatment was set up where $\mathrm{MB}$ were continuously generated during vegetable immersion in the ozonated solutions (bubbling $\mathrm{OMB}$ ). In these treatments $\mathrm{O}_{3}$ microbubbling was continued to maintain the concentration of dissolved $\mathrm{O}_{3}$ at $2.0 \mathrm{ppm}$ for 0,5 , or $10 \mathrm{~min}$ vegetable immersion.

A control treatment was also conducted where the vegetables were immersed in dechlorinated water. The solution temperature was maintained at $20{ }^{\circ} \mathrm{C}$ during all treatments and the concentrations of dissolved $\mathrm{O}_{3}$ were measured using an $\mathrm{OZ}-21 \mathrm{P} \mathrm{O}_{3}$ analyzer with a $\mathrm{DO}_{3}$ electrode. All analyses were performed in triplicate.

\subsection{Residual pesticides analysis}

Lettuce leaves or fruits of cherry tomato or strawberry $(20 \mathrm{~g})$ and $100 \mu \mathrm{L}$ of $20 \mathrm{ppm} \mathrm{d} 6$-FT as internal standard were added with liquid nitrogen, homogenized for 3 min by a blender 
(18000 rpm, Nissei Co. Ltd., Aichi, Japan), and then extracted by shaking in $100 \mathrm{~mL}$ of acetone for $30 \mathrm{~min}$. After the extraction was filtered with a glass filter under reduced pressure and was evaporated until about $5 \mathrm{ml}$ by a rotary evaporator, the extraction was added $5 \mathrm{~mL}$ of distilled water, and then was poured into a diatomite column (CHEM ELUT-20mL, UNBUFFERED, 100/PK, VARIAN Technologies Japan, Co. Ltd., Tokyo, Japan). The column was washed with $10 \mathrm{ml}$ of hexane at twice, the pesticide followed by $120 \mathrm{ml}$ of hexane to elute. The elution was evaporated to dryness by a rotary evaporator and refused in $2 \mathrm{ml}$ of acetone, and this solution $(10 \mu \mathrm{L})$ was injected into Gas Chromatograph-Mass Spectrometry.

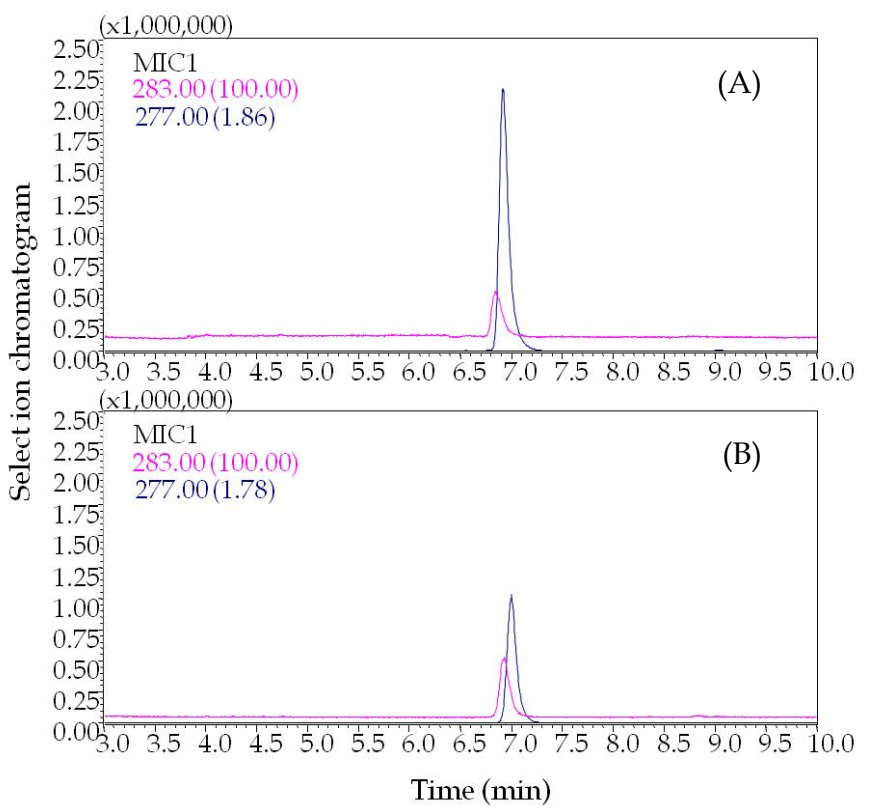

Figure 3. GC-chromatogram of fenitrothion and $\mathrm{d}_{6}$ - fenitrothion before and after OMB treatments. (A) before $\mathrm{O}_{3}$ treatment. (B) after $\mathrm{O}_{3}$ treatment.

A Shimadzu GC-MS QP2010 (Shimadzu Co., Ltd., Kyoto, Japan) was used for the analysis, with ionization achieved by electron impact at $70 \mathrm{eV}$. The capillary column used was an Inertcap 1MS capillary column (30 m $\times 0.25 \mathrm{~mm}$ i.d.; J\&W Scientific, Folsom, CA). The operating conditions were: injection port temperature, $250^{\circ} \mathrm{C}$; interface temperature, $280^{\circ} \mathrm{C}$; column oven temperature, $200{ }^{\circ} \mathrm{C}$ for $5 \mathrm{~min}$, ramped at $1{ }^{\circ} \mathrm{C} / \mathrm{min}$ to $215^{\circ} \mathrm{C}$, followed by $20^{\circ} \mathrm{C} / \mathrm{min}$ to $280^{\circ} \mathrm{C}$; helium carrier gas (flow rate of $30 \mathrm{~cm} / \mathrm{s}$ ); $10 \mu \mathrm{L}$ injection volume. The split/splitless injector was operated in the splitless mode for $0.5 \mathrm{~min}$ after injection of the sample. The selected ion of the labeled standard ( $\left.\mathrm{d}_{6}-\mathrm{FT}\right)$ was analyzed in the single ion monitoring (SIM) mode and the intensity calculated by a Shimadzu GC-MS solution. SIM of $\mathrm{d}_{6}-\mathrm{FT}$ used the ion: for $\mathrm{d}_{6}-\mathrm{FT}, \mathrm{m} / \mathrm{z}=283$; for FT, $\mathrm{m} / \mathrm{z}=277$ were quantification. Analyses were run in triplicate. Chromatogram and mass spectra of FT and $d_{6}$-FT were shown in Figure 3 and 4 , respectively. 


\subsection{Statistical analysis}

Mean separation of $\mathrm{O}_{3}$ concentration, residual percentage of FT and concentration of FT in vegetables between treatments were determined by Turkey-Kramer test at $\mathrm{P}<0.05$ and standard division of the mean (SD).

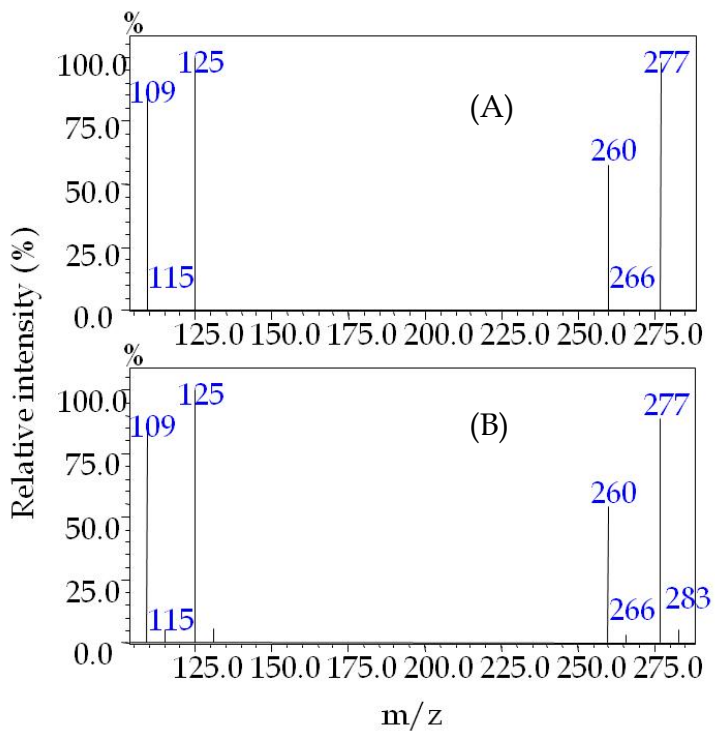

Figure 4. Mass spectrum of fenitrothion and $\mathrm{d}_{6}$ - fenitrothion (A) fenitrothion, (B) $\mathrm{d}_{6}$-fenitrothion

\section{Results and discussion}

\subsection{Removal of residual pesticide, fenitrothion, in vegetables by using OMB generated by different methods (Experiment 1)}

Figure 5 shows the change in the concentration of dissolved $\mathrm{O}_{3}$ in solutions after the start of $\mathrm{OMB}$ treatments with the gas-water circulation type and the decompression type. In both solutions, measured in the absence of vegetables, the concentration of dissolved $\mathrm{O}_{3}$ decreased gradually with time, and the concentration at 5 and $10 \mathrm{~min}$ after the start of OMB treatments was 1.3 and $1.0 \mathrm{ppm}$ in the gas-water circulation type solution, and 1.6 and $1.4 \mathrm{ppm}$ in the decompression type solution, respectively. Thus, the concentration of dissolved $\mathrm{O}_{3}$ was kept higher in the decompression type solution than in the gas-water circulation type solution. The half-life of dissolved $\mathrm{O}_{3}$ by using an air pump is reported to be $2.27 \mathrm{~min}$ in tap water at $25^{\circ} \mathrm{C}$ (Dhillon et al., 2009). That by using the gas-water circulation type was about $10 \mathrm{~min}$ and that by using the decompression type was much longer, though the solution temperature was $20^{\circ} \mathrm{C}$ in this study.

Figure 6 shows the residual percentage of FT in lettuce (A), cherry tomatoes (B) and strawberries (C) at 5 and $10 \mathrm{~min}$ after the immersion into the solutions of OMB treatments 


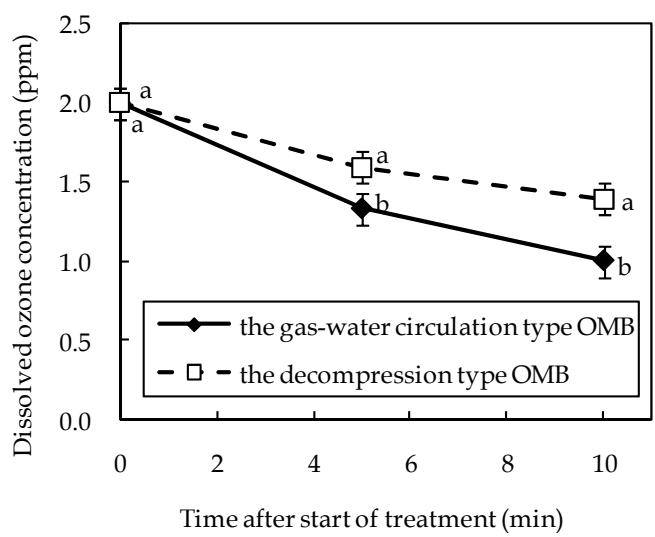

Figure 5. Change in the $\mathrm{DO}_{3}$ concentrations after $\mathrm{OMB}$ treatments by using the gas-water circulatingtype and the decompression-type.

Vertical bars represent the standard division of the mean $(n=3)$.

Different letters indicate a difference significant at the $5 \%$ level by Turkey-Kramer test between treatments.

by using the gas-water circulation type and the decompression type. In lettuce, the concentration of residual FT after washing in water was $212.21 \mathrm{ppm}$ (Table 1), and the concentration rapidly decreased after the start of both the treatments of the decompression type and the gas-water circulation type, reaching 44 and $55 \%$ at $5 \mathrm{~min}$, and 33 and $45 \%$ at 10 min, respectively. Thus, in lettuce, both the treatments of the decompression type and the gas-water circulation type removed residual FT effectively, and the decompression type was more effective than the gas-water circulation type. The dissolved $\mathrm{O}_{3}$ in the solutions of $\mathrm{OMB}$ treatments generates hydroxyl radicals that are highly effective at decomposing organic molecules like the residual FT (Sumikura et al, 2007; Takahashi et al., 2007b), and hydroxyl radicals are generated by the collapse of OMB in solutions (Chu et al., 2008a). The decompression type would have generated a high enough concentration of dissolved $\mathrm{O}_{3}$ to produce a large amount of hydroxyl radicals. However, the gas-water circulation type was lower effective than the decomposing type, because the concentration of dissolved $\mathrm{O}_{3}$ was lower and fewer hydroxyl radicals would have been generated.

In cherry tomatoes, the concentration of FT after washing with water was $3.02 \mathrm{ppm}$ (Table 1 ), and the residual FT percentage at $5 \mathrm{~min}$ after the start of OMB treatments of the decompression type and the gas-water circulation type was 89 and $97 \%$, respectively, showing a low pesticide-removing effect. At $10 \mathrm{~min}$ after the start of OMB treatments, it was 84 and 95\%, respectively. Thus, the decompression type was slightly more effective than the gas-water circulation type. The most likely explanation for the lower reduction of residual FT in cherry tomatoes is that the dissolved $\mathrm{O}_{3}$ and hydroxyl radicals could not penetrate through the thick pericarp of the cherry tomatoes and not reach the sarcocarp, and were inactivated by contact with the pericarp.

In strawberries, the concentration of FT after washing with water was 37.80 ppm (Table 1), and the residual percentage of FT at $5 \mathrm{~min}$ after the start of OMB treatments of the 


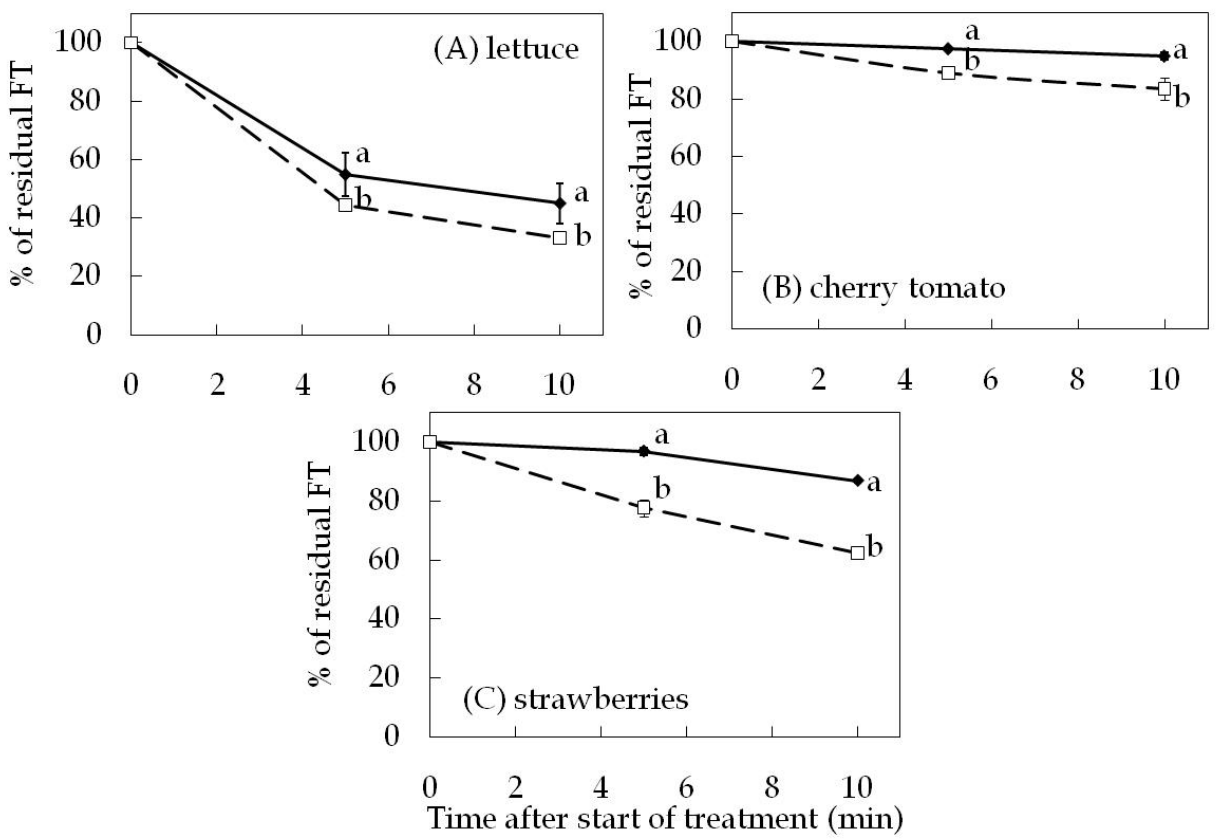

the gas-water circulation type OMB - - - the decompression type OMB

Figure 6. Residual fenitrothion percentages for lettuce (A), cherry tomatoes (B), and strawberries (C) after immersion in solutions containing OMB generated by using the gas-water circulating-type and the decompression-type.

Vertical bars represent the standard division of the mean $(n=3)$.

Different letters indicate a difference significant at the $5 \%$ level by Turkey-Kramer test between treatments.

decompression type and the gas-water circulation type was 78 and $97 \%$, respectively. That at $10 \mathrm{~min}$ after the start of $\mathrm{OMB}$ treatments of the decompression type and the gas-water circulation type was 62 and $87 \%$, respectively, showing that the pesticide could be removed effectively by using the decompression type. The amount of FT removed in strawberries was higher than that in cherry tomatoes at both types of $\mathrm{OMB}$ generators. We think that strawberries have a rougher surface and larger surface area than cherry tomatoes and then can contact with $\mathrm{O}_{3}$ efficiently, removing FT easily in the sarcocarp.

The decompression type had a high FT-removing effect on all vegetables examined even though the initial concentration of dissolved $\mathrm{O}_{3}$ was $2.0 \mathrm{ppm}$. The difference in the pesticideremoving effect between the decompression type and the gas-water circulation type may be caused by the difference in the size and the number of the bubbles (Takahashi, 2009). The diameter of the MB generated using the decompression type shows about $10 \mu \mathrm{m}$, and the number of bubbles smaller than $50 \mu \mathrm{m}$ in diameter amounted to several thousand per $\mathrm{ml}$ (Takahashi et al., 2007a). On the other hand, the diameter of the MB generated using the gaswater circulation type shows about $40 \mu \mathrm{m}$, and the number of MB smaller than $50 \mu \mathrm{m}$ in 


\begin{tabular}{|c|c|c|c|c|c|c|c|c|c|}
\hline & \multicolumn{7}{|c|}{ Concentration (ppm) } & \multicolumn{2}{|c|}{ Coefficient of variation (\%) } \\
\hline \multirow{5}{*}{ lettuce } & Time & $\begin{array}{l}\text { The gas- } \\
\text { water } \\
\text { circulation } \\
\text { type OMB }\end{array}$ & \pm & $\mathrm{SD}$ & $\begin{array}{c}\text { The } \\
\text { decompres } \\
\text { sion type } \\
\text { OMB }\end{array}$ & \pm & SD & $\begin{array}{c}\text { The gas-water } \\
\text { circulation } \\
\text { type OMB }\end{array}$ & $\begin{array}{c}\text { The } \\
\text { decompress- } \\
\text { sion type } \\
\text { OMB }\end{array}$ \\
\hline & $\begin{array}{c}\text { before } \\
z\end{array}$ & 346.64 & \pm & 5.75 & 346.64 & \pm & 5.75 & 1.66 & 1.66 \\
\hline & 0 & 212.21 & \pm & $\begin{array}{c}31.2 \\
4\end{array}$ & 212.21 & \pm & 31.24 & 14.72 & 14.72 \\
\hline & 5 & 117.77 & \pm & 4.30 & 95.11 & \pm & 1.96 & 3.65 & 2.06 \\
\hline & 10 & 96.50 & \pm & 0.79 & 92.75 & \pm & 3.93 & 0.82 & 4.24 \\
\hline \multirow{4}{*}{ tomatoes } & before & 3.41 & \pm & 0.14 & 3.41 & \pm & 0.14 & 4.05 & 4.05 \\
\hline & 0 & 3.02 & \pm & 0.17 & 3.02 & \pm & 0.17 & 5.70 & 5.70 \\
\hline & 5 & 2.75 & \pm & 0.04 & 2.70 & \pm & 0.11 & 1.50 & 4.08 \\
\hline & 10 & 2.75 & \pm & 0.12 & 2.53 & \pm & 0.23 & 4.25 & 9.00 \\
\hline \multirow{4}{*}{$\begin{array}{l}\text { Straw- } \\
\text { berries }\end{array}$} & before & 43.50 & \pm & 2.12 & 43.50 & \pm & 2.12 & 4.88 & 4.88 \\
\hline & 0 & 37.80 & \pm & 4.58 & 37.80 & \pm & 4.58 & 12.11 & 12.11 \\
\hline & 5 & 34.80 & \pm & 4.12 & 29.35 & \pm & 2.18 & 11.84 & 7.44 \\
\hline & 10 & 32.25 & \pm & 3.07 & 23.59 & \pm & 0.15 & 9.53 & 0.62 \\
\hline
\end{tabular}

${ }^{\mathrm{z}}$ before washing in tap water.

Table 1. Concentration of residual FT for lettuce, cherry tomatoes, and strawberries after immersion in solutions containing $\mathrm{OMB}$ generated by using the gas-water circulating-type and the decompressiontype.

diameter amounted to several hundred per $\mathrm{ml}$, which is less than that of the decompression type (Takahashi et al., 2003). These findings show that the decompression type had a strong pesticide-removing effect, which could be attributed to the larger number of small OMB that could more easily infiltrate into the vegetables than the gas-water circulation type. There have been no reports on the effects of OMB generated by different methods on the removal of residual pesticides in vegetables. This is the first report showing the pesticide-removing effect of OMB with the different methods of generation. In this study, we tested that whether vegetable containing in high concentration of pesticide was removed or not, and so we confirmed that vegetables were removed efficiently by treatment with the OMB. In near future, we should be attempted to confirm safety of vegetable treated by OMB.

\subsection{Removal of residual pesticides in vegetables using OMB dissolved by different concentration (Experiment 2)}

Experiment 1 was conducted, in the absence of any vegetables, to determine how dissolved $\mathrm{O}_{3}$ concentrations changed in the ozonated water solutions over time at $20^{\circ} \mathrm{C}$. Figure 7 
shows how the concentration of dissolved $\mathrm{O}_{3}$ changed over a 10 minute period (the maximum length of subsequent vegetable treatments), once the ozonated water solutions had been prepared. Over the 10 min period the concentration of dissolved $\mathrm{O}_{3}$ in the $\mathrm{MB}$ solution with a starting concentration of $2.0 \mathrm{ppm}$ (2.0 ppm OMB solution) decreased steadily to $1.0 \mathrm{ppm}$ Similarly, the concentrations of dissolved $\mathrm{O}_{3}$ in the 0.5 and $1.0 \mathrm{ppm} \mathrm{OMB}$ solutions, and the 0.2 ppm OMLB solution also decreased steadily, with all dissolved $\mathrm{O}_{3}$ lost from the $0.5 \mathrm{ppm}$ OMB and $0.2 \mathrm{ppm}$ OMLB solutions within 10 minutes.

Figure 8 shows the reduction in residual FT in lettuce treated with the OMB and OMLB solutions. Before treatment with OMLB or OMB solutions, but after washing with tap water, the concentration of residual FT in lettuce was $212.2 \mathrm{ppm}$ (data not shown). The amount of residual FT decreased with increasing treatment time and dissolved $\mathrm{O}_{3}$ concentration. The residual FT in lettuce was reduced to $67 \%, 55 \%$ and $45 \%$ after 5 minutes treatment with the 1.0 ppm OMB, 2.0 ppm OMB, and 2.0 ppm bubbling OMB solutions, respectively. After 10 minutes treatment the respective amounts of residual FT had been further reduced to $49 \%$, $45 \%$ and $42 \%$. The similarly high reductions in residual FT achieved with the $1.0 \mathrm{ppm} \mathrm{OMB}$, $2.0 \mathrm{ppm} \mathrm{OMB}$, and $2.0 \mathrm{ppm}$ bubbling $\mathrm{OMB}$, indicates that immersion of lettuce in an $\mathrm{OMB}$ solution containing $1.0 \mathrm{ppm}$ or more dissolved $\mathrm{O}_{3}$ may be sufficient to effectively remove residual FT from the lettuce, possibly because lettuce has thin leaves. In contrast, after 10 minutes treatment with the OMLB and 0.5 ppm OMB solutions the residual FT had only been reduced to $87 \%$ and $78 \%$, respectively.

The dissolved $\mathrm{O}_{3}$ in the $\mathrm{OMB}$ treatment solutions generates hydroxyl radicals that are highly effective at decomposing organic molecules like the residual FT (Sumikura et al., 2007; Takahashi et al., 2007b). Hydroxyl radicals are generated by the collapse of OMB in solution, and so the $1.0 \mathrm{ppm} \mathrm{OMB}, 2.0 \mathrm{ppm} \mathrm{OMB}$ and bubbling OMB solutions would have had a high enough concentration of dissolved $\mathrm{O}_{3}$ to produce a large amount of hydroxyl radicals. However, the OMLB treatment was not nearly so effective because the concentration of dissolved $\mathrm{O}_{3}$ was much lower and so far fewer hydroxyl radicals would have been generated.

Figure 9 shows the reduction of residual FT in cherry tomatoes for each treatment. The starting concentration of residual FT in the cherry tomatoes was $3.0 \mathrm{ppm}$ (data not shown), prior to $\mathrm{O}_{3}$ solution treatments. Removal of residual FT by the various treatment solutions was much less in the cherry tomatoes than in the lettuce. After 10 minutes treatment residual FT had been reduced to $65 \%$ in 2.0 ppm bubbling OMB solution, but remained at $>90 \%$ for all other treatments. The most likely explanation for the lower reduction of residual FT in the cherry tomatoes is that the dissolved $\mathrm{O}_{3}$ and hydroxyl radicals could not penetrate through the thick pericarp of the tomatoes and to reach the sarcocarp, and were inactivated by contact with the pericarp. The greater effectiveness of the bubbling OMB solution was probably because the concentration of dissolved $\mathrm{O}_{3}$ remained high and so hydroxyl radicals continued to be generated throughout the treatment.

Figure 10 shows the reductions in residual FT in strawberries for each treatment. The starting concentration of residual FT in strawberries was 37.8 ppm (data not shown). After $10 \mathrm{~min}$ of 
treatment, the greatest reduction in residual FT was in the $2.0 \mathrm{ppm}$ bubbling OMB treatment where $75 \%$ residual FT remained. The other treatments ranged from $85 \%$ residual FT remaining in the $2.0 \mathrm{OMB}$ treatment to $91 \%$ in the OMLB treatment. The amount of FT that

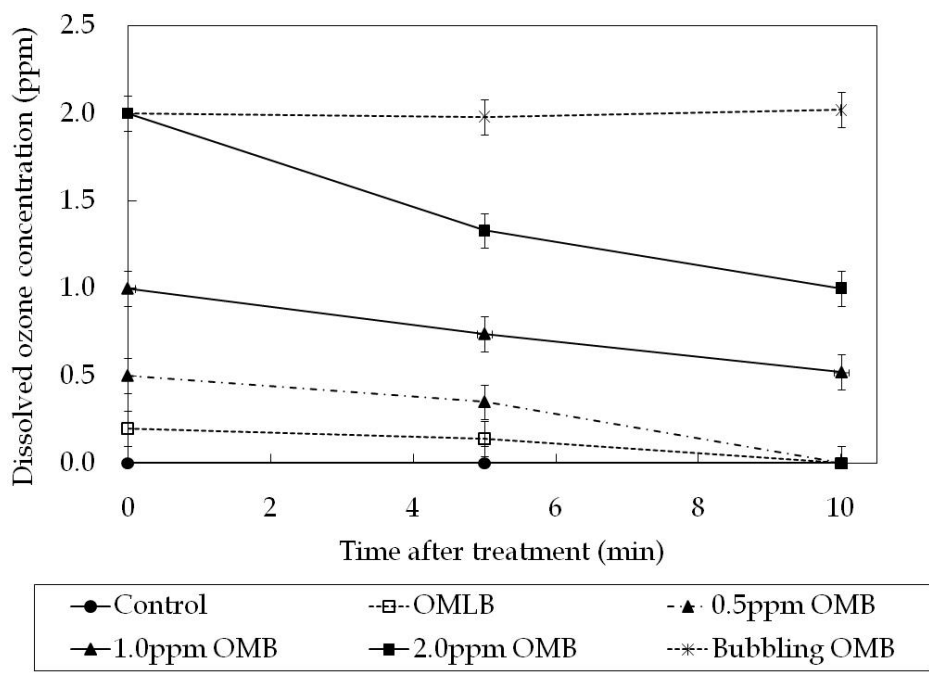

Figure 7. Change in the concentration of dissolved $\mathrm{O}_{3}$ after the start of the $\mathrm{O}_{3}$ treatments, in the absence of vegetables.

Vertical bars represent one standard deviation of the mean.

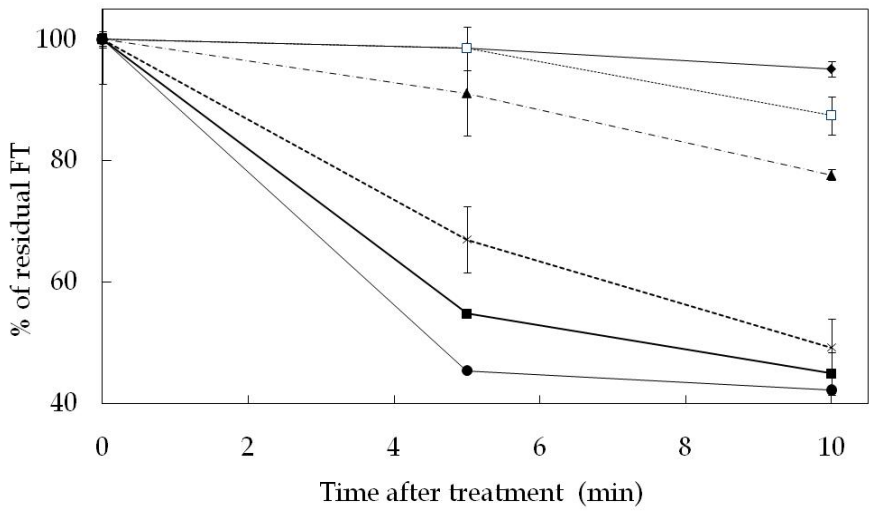

\begin{tabular}{|lll}
$\rightarrow-$ Control & $-\square \mathrm{OMLB}$ & $-\mathbf{- 0 . 5} \mathrm{ppm} \mathrm{OMB}$ \\
$-\cdots-1.0 \mathrm{ppm} \mathrm{OMB}$ & $\rightarrow-2.0 \mathrm{ppm} \mathrm{OMB}$ & - bubbling OMB \\
\hline
\end{tabular}

Figure 8. Change in the residual FT in lettuce treated with the OMB and OMLB solutions. Vertical bars represent the standard deviation of the mean. 


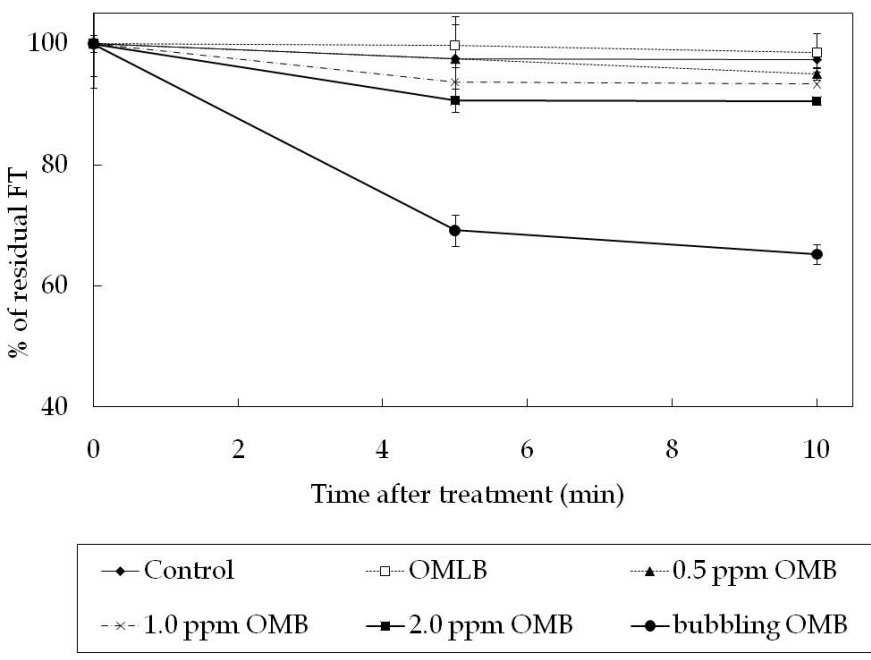

Figure 9. Change in the residual FT in cherry tomatoes treated with the OMB and OMLB solutions. Vertical bars represent the standard deviation of the mean.

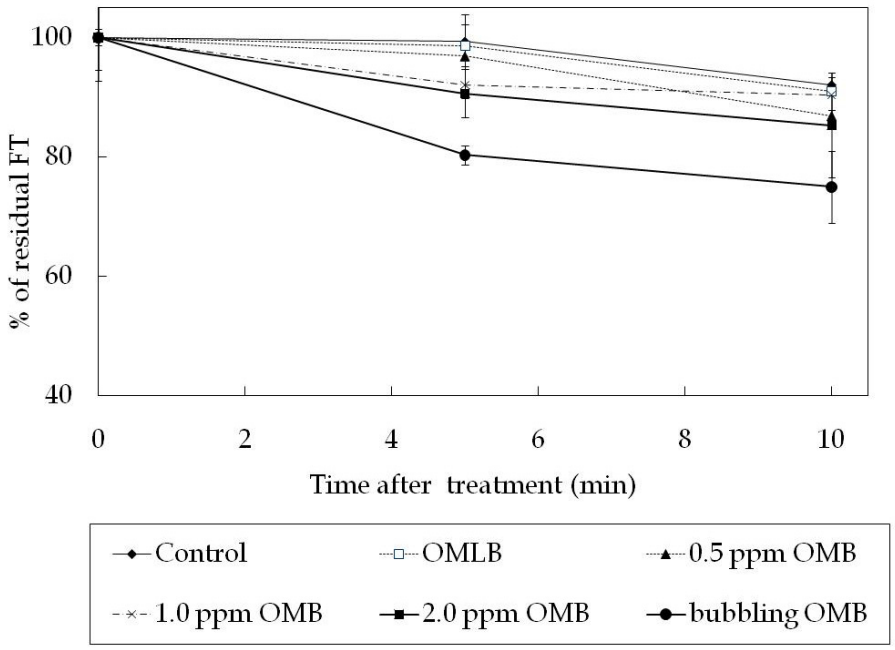

Figure 10. Change in the residual FT in strawberries treated with the OMB and OMLB solutions. Vertical bars represent the standard deviation of the mean.

was removed with the $2.0 \mathrm{ppm}$ bubbling $\mathrm{OMB}$ solution was lower than that in the cherry tomatoes. Strawberries have a rougher surface and larger surface area than cherry tomatoes and this may cause $\mathrm{O}_{3}$ and hydroxyl radicals to lose their specific activity upon contact with the surface of strawberries, preventing them from removing FT in the sarcocarp. 
There have been several studies on the decomposition of pesticides by $\mathrm{O}_{3}$ treatment (Daidai et al., 2007; Hwang et al., 2001a; Hwang et al., 2001b; Hwang et al., 2002; Karaca and Velioglu, 2007; Ong et al, 1995; Wu et al., 2007a). For example, it was reported that 140 ppm FT was completely decomposed within $40 \mathrm{~min}$ in $13 \%$ ozonated solution produced by millibubbling (Tanaka et al., 1992). Another study reported that $53 \%$ of diazinon, $55 \%$ of parathion, $47 \%$ of methyl parathion, and $61 \%$ of cypermethrin were removed from the brassicaceous vegetable "Pakchoi" (Brassica campestris L. ssp. chinensis Makino) treated with $0.1 \mathrm{ppm}$ of these pesticides and then immersed in ozonated solution containing $2.0 \mathrm{ppm}$ dissolved $\mathrm{O}_{3}$ for $30 \mathrm{~min}$ ( $\mathrm{Wu}$ et al., 2007b). A further study demonstrated that $2.0 \mathrm{ppm}$ residual captan, azinphos-methyl, and formetanate $\mathrm{HCl}$ on the surface of apples after harvest were reduced effectively by immersing them in $0.25 \mathrm{ppm} \mathrm{O}$-millibubbled solution for $30 \mathrm{~min}$ (Ong et al., 2007a). Although these studies show that residual pesticides can be removed from vegetables and fruits by immersion in ozonated solution, prior to our study there had not been any reports on using these techniques to remove residual pesticides from fruity vegetables such as tomatoes and strawberries. Interestingly, one report showed that 11 kinds of pesticides (alachlor, atrazine, bentazon, butylate, carbofuran, cyanazine, 2,4dichlorophenoxyacetic acid, malathion, metolachlor, metribuzin, and trifluralin) could be removed by $\mathrm{O}_{3}$ generation ( $454 \mathrm{~g} \mathrm{O}_{3} /$ day) and $\mathrm{UV}$ irradiation, but several hours of treatment were necessary (Philip et al., 1987).

Clearly, residual pesticides in leafy vegetables can be removed by immersion in ozonated solution, but the concentrations of residual pesticide in the earlier studies were low. In the present study, high concentration of residual FT founded in lettuce ( $>200 \mathrm{ppm}$ ) could be reduced to less than $100 \mathrm{ppm}$ in 5-10 min by treatment with 1.0-2.0 ppm OMB solution. Such a large reduction may be possible because the chemical structure of FT is similar to diazinon, which can be easily decomposed by hydroxyl radicals (Kouloumbos et al., 2003), and so the oxidative powers of $\mathrm{O}_{3}$ and hydroxyl radicals may act in concert to effectively degrade FT. This effective joint action was only possible in the MB generated solutions because the millibubble generated solutions could not achieve high enough dissolved $\mathrm{O}_{3}$ concentrations and not generate hydroxyl radicals.

This study showed that $\mathrm{OMB}$ can remove high concentrations of residual pesticides within a short time from not only leafy vegetables but also fruity vegetables. Thus, OMB could be useful for removing residual pesticides from a wide range of vegetables. In near future, we should be attempted to confirm the quality and safety of vegetable and fruits treated by OMB.

\section{Conclusion}

The effectiveness of OMB for removal of residual pesticides varies with the methods of the $\mathrm{OMB}$ generation. The decompression type was more effective than the gas-water circulation type on removing the residual pesticide in vegetables, which could be attributed to the larger number of small OMB that could more easily infiltrate into vegetables than the gaswater circulation type. 
OMB quickly and effectively removed high concentrations of residual FT from lettuce. In addition, continuously bubbled OMB effectively removed residual FT from fruity vegetables with a thick pericarp and sarcocarp, such as cherry tomatoes and strawberries. Unlike millibubbles, $\mathrm{MB}$ allow $\mathrm{O}_{3}$, which is highly insoluble in water, to be easily dissolved in water at high concentrations. As a result, OMB solutions are more effective than OMLB solutions at removing residual pesticides from vegetables because the OMB solutions combine the oxidative power of $\mathrm{O}_{3}$ with the generation of hydroxyl radicals from the collapsing OMB.

\section{Author details}

Masahiko Tamaki and Hiromi Ikeura

Meiji University, Japan

\section{Acknowledgement}

This work was supported by grant-aid for scientific research (C) (21580407) from Japan Society for the Promotion of Science.

\section{References}

Cataldo, F. (2008). Ozone Decomposition of Patulin-A Micotoxin and Food Contaminant, Ozone: Science E Engineering, Vol.30, No.3, (May 2008), pp. 197-201, ISSN 0191-9512

Chu, L. B.; Xing, X. H.; Yu, A. F.; Zhou, Y. N.; Sun, X. L. \& Jurcik, B. (2007). Enhanced ozonation of simulated dyestuff wastewater by microbubbles, Chemosphere, Vol.68, No.10, (August 2007), pp. 1854-1860, ISSN 0045-6535

Chu, L. B.; Yan, S. T.; Xing, X. H.; Yu, A. F.; Sun, X. L. \& Jurcik, B. (2008a). Enhanced sludge solubilization by microbubble ozonation, Chemosphere, Vol.72, No.2, (May 2008), pp. 205-212, ISSN 0045-6535

Chu, L. B.; Xing, X. H.; Yu, A. F.; Sun, X. L. \& Jurcik, B. (2008b). Enhanced treatment of practical textile wastewater by microbubble ozonation, Process Safety and Environmental Protection, Vol.86, No.5, (September 2008), pp. 389-393, ISSN 0957-5820

Daidai, M.; Kobayashi, F.; Mtsui, G. \& Nakamura, Y. (2007). Degradation of 2,4dichlorophenoxyacetic acid (2,4-D) by ozonation and $\mathrm{TiO}_{2} / \mathrm{UV}$ treatment, Journal Chemical Engineering Japan, Vol.40, No.9, (September 2008), pp. 378-384, ISSN 1001-0742

Dhillon, B.; Wiesenborn, D.; Wolf-Hall, C. \& Manthey, F. (2009). Development and Evaluation of an Ozonated Water System for Antimicrobial Treatment of Durum Wheat, Journal of Food Science, Vol.74, No.7, (September 2009), pp. E396-E403, ISSN 17503841

Hwang, E.-S.; Cash, J. N. \& Zabik, M. J. (2001a). Postharvest treatments for the reduction of Mancozeb in fresh apples, Journal of Agricultural and Food Chemistry, Vol.49, No.6, (May 2001), pp. 3127-3132, ISSN 0021-8561 
Hwang, E.-S.; Cash, J. N. \& Zabik, M. J. (2001b). Ozone and hydrogen peroxyacetic acid treatment to reduce or remove EBDCs and ETU residues in solution, Journal of Agricultural and Food Chemistry, Vo.49, No.11, (November 2011), pp.5689-5694, ISSN 0021-8561

Hwang, E.-S.; Cash, J. N. \& Zabik, M. J. (2002). Degradation of Mancozeb and Ethylenethiourea in apples due to postharvest treatments and processing, Journal of Food Science, Vol.67, No.9, (November 2002), pp. 3295-3300, ISSN 1750-3841

Gabler, F. M.; Smilanick, J. L. Mansour, M. F. \& Karaca, H. (2010). Influence of fumigation with high concentrations of ozone gas on postharvest gray mold and fungicide residues on table grapes, Postharvest Biology and Technology, Vol.55, No.2, (February 2010), pp. 8590, ISSN 0925-5214

Karaca, H. \& Velioglu, Y. S. (2007). Ozone applications in fruit and vegetable processing, Food Reviews Internationl, Vol.23, No.1, (February 2007), pp. 91-106, ISSN 8755-9129

Karaca, H. \& Velioglu, Y. S. (2009). Effects of Some Metals and Chelating Agents on Patulin Degradation by Ozone, Ozone: Science E Engineering, Vol.31, No.3, (May 2009), pp. 224 231, ISSN 0191-9512

Karaca, H.; Velioglu, Y. S. \& Nas, S. (2010). Mycotoxins: contamination of dried fruits and degradation by ozone, Toxin Reviews, Vol.29, No.2, (May 2010), pp. 51-59, ISSN 15569543

Khadre, M. A.; Yousef, A. E. \& Kim, J. G. (2001). Microbial aspects of ozone applications in food: a review, Journal of Food Science, Vol. 66, No. 9, (November 2001), pp. 1242-1252, ISSN 0022-1147.

Kobayashi, F.; Hayata, Y.; Ikeura, H.; Tamaki, M.; Muto, N. \& Osajima, Y. (2009). Inactivation of Escherichia coli by $\mathrm{CO}_{2}$ microbubbles at a lower pressure and near room temperature, Transactions of the ASABE, Vo.52, No.5, (May 2009), pp.1621-1626, ISSN 0001-2351

Kouloumbos, V. N.; Tsipi, D. F.; Hiskia, A. E.; Nicolic, D. \& Van Breeman, R. B. (2003). Identification of photocatalytic degradation products of diazinon in $\mathrm{TiO}_{2}$ aqueous suspensions using GC/MS/MS and LC/MS with quadrupole time-of-flight mass spectrometry, Journal of the American Society for Mass Spectrometry, Vol.14, No.8, (August 2003), pp. 803-817, ISSN 1044-0305

Li, P. \& Tsuge, H. (2006). Ozone transfer in a new gas-induced contactor with microbubbles, Journal of Chemical Engineering of Japan, Vol.39, No.11, (May 2006), pp. 1213-1220, ISSN 0021-9592

Mahapatra, A. K.; Muthukumarappan, K. \& Julson, J. L. (2005). Applications of ozone, bacteriocins, and irradiation in food processing: a review, Critical Reviews in Food Science and Nutrition, Vol.45, No.6, (January 2005), pp. 447-461, ISSN 1040-8398

Ong, K. C.; Cash, J. N.; Zabik, M. J.; Siddiq, M. \& Jones, A. L. (1996). Chlorine and ozone washes for pesticide removal from apples and processed apple sauce, Food Chemistry, Vol.55,No.2, (March 1996), pp. 153-160, ISSN 0308-8146

Park, J. S. \& Kurata, K. (2009). Application of microbubbles to hydroponics solution promotes lettuce growth, HortTechnology, Vol.19, No.1, (January 2009), pp. 212-215, ISSN 1063-0918 
Philip, C. K.; Muldoon, M. T. \& Somich, C. J. (1987). UV-ozonation of eleven major pesticides as a waste disposal pretreatment, Chemosphere, Vol.16, No.10-12, (October 1987), pp. 2321-2330, ISSN 0045-6535

Sumikura, M.; Hidaka, M.; Murakami, H.; Nobutomo, Y. \& Murakami, T. (2007). Ozone micro-bubble disinfection method for wastewater reuse system, Water Science $\mathcal{E}$ Technology, Vol.56, No.5, (May 2007), pp. 53-61, ISSN 0273-1223

Takahashi, M.; Kawamura, T.; Yamamoto, Y.; Ohnari, H.; Himuro, S. \& Shakutsui, H. (2003). Effect of shrinking microbubble on gas hydrate formation, Journal of Physical Chemistry B, Vol.107, No.10, (February 2003), pp. 2171-2173, ISSN 1520-6106

Takahashi, M.; Chiba, K. \& Li, P. (2007a). Free-radical generation from collapsing microbubbles in the absence of a dynamic stimulus, Journal of Physical Chemistry B, Vol.111, No.14, (January 2007), pp. 1343-1347, ISSN 1520-6106

Takahashi, M.; Chiba, K. \& Li, P. (2007b). Formation of hydroxyl radicals by collapsing ozone microbubbles under strongly acidic conditions, Journal of Physical Chemistry B, Vol.111, No.14, (September 2007), pp. 11443-11446,ISSN 1520-6106

Takahashi, M. (2009). Base and technological application of micro-bubble and nano-bubble, Materials Integration, Vol.22, No.5, (September 2009), pp. 2-19, ISSN 1344-7858

Tanaka, K.; Abe, K.; Sheng, C. Y. \& Hisanaga, T. (1992). Photocatalytic wastewater treatment combined with ozone pretreatment, Environmental Science \& Technology, Vol.26, No.12, (December 1992), pp. 2534-2536, ISSN 0013-936X

Yamaguchi, Y. (2006). Environmental and food hygiene approach to pesticide, Seilatsu Eisei, Vol.50, No.5, (October 2006), pp. 283-290, ISSN 0582-4176

US Environmental Protection Agency (2008). National ambient air quality standards for ozone, Federal Register, Vol.73, No.60, (March 2008), pp. 16436-16514, ISSN

Wu, J. G.; Luan, T.; Lan, C.; Lo, T. W. H. \& Chan, G. Y. S. (2007a). Removal of residual pesticides on vegetable using ozonated water, Food Control, Vol.18, No.5, (May 2007), pp. 466-472, ISSN 0956-7135

Wu, J. G.; Luan, T. G.; Lan, C. Y.; Lo, W. H. \& Chan, G. Y. S. (2007b). Efficacy evaluation of low-concentration of ozonated water in removal of residual diazinon, parathion, methyl-parathion and cypermethrin on vegetable, Journal of Food Engineering, Vol.79, No.3, (April 2007), pp. 803-809, ISSN 0260-8774 